\title{
A new concept for the collection of an electron beam guided by an externally applied magnetic field
}

\author{
Ioannis Gr. Pagonakis ${ }^{1}$, Jean-Philippe Hogge ${ }^{1}$, Stefano Alberti ${ }^{1}$, \\ K. A. Avramides ${ }^{2}$ and J. L. Vomvoridis ${ }^{2}$ \\ ${ }^{1}$ Centre de Recherche en Physique des Plasmas,Association Euratom-Confédération Suisse, \\ EPFL Ecublens, Station 13, CH-1015 Lausanne, Switzerland \\ ${ }^{2}$ National Technical University of Athens, School of Electrical and Computer Engineering, \\ 9 Iroon Polytechniou st., GR 15773 Athens, Greece
}

A new concept for the collection of an electron beam which is guided by an externally applied magnetic field is presented. The two major advantages of the new idea are the significant increase of the collector efficiency and the reduction of the ohmic load on the collector wall. For the illustration of the new concept a collector has been designed for the hollow electron beam of the European $170 \mathrm{GHz}, 2 \mathrm{MW}$ coaxial gyrotron for ITER. The simulation shows that the efficiency of this advanced collector is more than $90 \%$. 